\title{
A comparative study of gravity and crustal deformation data through superconducting gravimeter and GPS observations in the North-West Himalayan region
}

\author{
Wadia Institute of Himalayan Geology, 33 GMS Road, Dehradun - 248 001. *Corresponding author E-mail: nkd@wihg.res.in
}

(Received: 10/12/2014; Accepted: 21/01/2016)

DOI:10.18814/epiiugs/2016/v39i4/103892

Simultaneous observations of gravity measurements and vertical crustal deformation are carried out at the Multi-Parametric Geophysical Observatory (MPGO), Ghuttu (Location $30.53^{\circ} \mathrm{N}, 78.74^{\circ} \mathrm{E}$ ) located in Northwestern part of Himalaya in India. The temporal variation of gravity measurements are monitored by a superconducting gravimeter while the crustal deformations are observed using a dual frequency GPS antenna and receiver system. The simultaneous data collected by both instruments during a period of $\sim 3$ years from 2007 to 2010 is evaluated. Both data sets show apparent seasonal/annual changes with a clear phase difference of few months causing negative correlation between the two time series. Loading effects on the Earth's uppermost crust due to the hydrological cycle, as measured from local water table record, are advocated as the explanation of the observed seasonal variation.

\section{Introduction}

Temporal changes in the gravity field originate from mass redistribution as well as from vertical crustal deformations. Based on high resolution records of high sensitive superconducting gravimeters (SG), absolute gravimeters (AG), Gravity Recovery and Climate Experiment (GRACE) data and Global Positioning System (GPS) measurements, the relation between the variation of the gravity field and vertical surface deformation has been observed around the globe (e.g. Zerbini et al., 2001; Amalvict et al., 2004; Francis et al., 2004; Rosat et al., 2009; Van Camp et al., 2010). The SG is able to monitor sub-micro-gal temporal variations of the gravity field at earth's surface due to small tectonic motions or mass distribution (Arora et al., 2012). In SG and GPS continuous time series, spatial as well as temporal variations have been proved and separate studies of both types of data have been carried out extensively (Crossley et al., 2004; Banerjee and Burgmann, 2002; Wilmes et al., 2006; Bettinelli et al., 2008; Fu and Freymueller, 2012; Khandelwal et al., 2014). As reported earlier superconducting gravimeters have attracted considerable attention among research workers for far accurate gravity field measurements, e.g. Crossely et al. (2004) examined the time varying gravity field over central Europe using eight SG stations. They observed significant annual variations in gravity records, which have been correlated mainly with regional hydrological models. Rosat et al. (2009) analysed ten year records of time-varying gravity at Strasbourg in France using SG data. They explained long-term effects and seasonal variations in gravity data in terms of hydrology and GPS measurements of vertical plate motion. Also, for the SG station presented here, Kumar et al. (2013) evaluated SG data records and found a strong influence of the hydrological cycle on gravity.

During the past three decades, the global positioning system (GPS) has been established as an important tool for the study of plate movements on boundaries and within tectonic plates (Jackson and Bilham, 1994; Gahalaut and Kundu, 2012; Aktug et al., 2013). In the Himalayan orogeny, early GPS measurements were performed mostly in campaign mode in the central Himalaya region around Nepal (Jackson and Bilham, 1994; Gahalaut and Chander, 1997; Burgmann et al., 1999). Later, GPS observations have also been carried out in NW Himalaya by employing several campaigns and permanent stations (Gahalaut and Chander, 1999; Banerjee and Burgmann, 2002; Ponraj et al., 2010). In general, all these studies reported spatial variations of plate movements. Furthermore, temporal variations in crustal deformation have also been reported. Crustal movement/ deformation may be influenced by temporal variations in different time domains/range (diurnal, seasonal and annual) due to various meteorological processes like monsoon, snow load, atmospheric pressure and temperature etc. (Bettinelli et al., 2008; Fu and Freymueller, 2012; Jin et al., 2012; Khandelwal et al., 2014).

In view of these facts, the first SG on the Indian continent was installed at the Multi-Parametric Geophysical Observatory (MPGO), Ghuttu $\left(30.53^{\circ} \mathrm{N}, 78.74^{\circ} \mathrm{E}\right)$ by the Wadia Institute of Himalayan Geology (WIHG), Dehradun, India in 2007. The MPGO, located in north-western part of the Himalaya, is the first of its kind in India established under the National Program of Earthquake Precursors 
(NPEP). In this setup, continuous monitoring of different geophysical and meteorological parameters is performed (Arora et al., 2008, 2012; Kumar et al., 2012, 2013; Khandelwal et al., 2014, 2015). Moreover, in this region of Himalaya the seismic activity is very high (Lyubushin et al., 2010; Kumar et al., 2012). Along with the SG data, rainfall, atmospheric pressure, atmospheric temperature, temperatures at different depths within a $68 \mathrm{~m}$ deep borehole and water level change in the borehole, radon concentration in soil and water, Broad Band Seismometer (BBS), accelerometer and GPS data are recorded. In this work, we present the results observed from SG and GPS records for a three year period from 2007 to 2010 . We found clear seasonal variations in both data sets. A phase difference in the annual cycles of both data sets is also observed.

\section{Experimental set up}

The parallel observations (SG and GPS) were initiated at MPGO in April 2007. The location of this station is shown in Figure 1 along with the tectonic and geological setting of the Himalaya and adjoining regions. The station is located in the western part of Himalaya and at the northern extent of Lesser Himalaya where the seismic activity is very high. Recently observed micro-earthquake and higher magnitude seismicity is quite high around this station (Figure 2). Recently two strong earthquakes (Ms 6.6 Uttarkashi, 1991 and Ms 6.4 Chamoli, 1999) occurred nearby within the seismic gap for major and devastating earthquakes reported in the catalogue of past seismic activity of the Himalayan region (Figure 1). The station is situated almost on the Main Central Thrust (MCT), which is the seismically most active tectonic feature of Himalaya. A very high microearthquake activity is reported around this tectonic discontinuity (Pandey et al., 1995; Kumar et al., 2012).

The detailed description of the SG at MPGO Ghuttu is given by Arora et al. (2008). At this station, a dual frequency TOPCON GPS system for highly accurate observations of temporal surface deformation is installed observing all three components of the displacement vector every $30 \mathrm{sec}$ with micrometer accuracy. The GPS antenna is installed at an open place within the MPGO campus away from any building or towering objects, to avoid multipath errors. The antenna stands on a concrete pillar of $5.48 \mathrm{~m}$ height, 90 percent part of the pillar is below the ground surface.

\section{Data and method of analysis}

The SG records temporal gravity variations in volts at a sampling rate of $1 \mathrm{~Hz}$. The SG of Ghuttu station is a dual sphere gravimeter. The recorded values are first converted to gravity units $\left(\mathrm{nm} / \mathrm{s}^{2}\right)$ using calibration factors obtained by least squares adjustment. The calibration factor is $810.5 \mathrm{~nm} / \mathrm{s}^{2} / \mathrm{V}$ for the lower sphere and 749.7 $\mathrm{nm} / \mathrm{s}^{2} / \mathrm{V}$ for the upper sphere. As reported by Arora et al. (2012) tidal effects are eliminated from the gravity data using ANALYSE program of ETERNA 3.3 software (Wenzel, 1996). The value of admittance coefficient is $-3.2 \mathrm{nms}^{-2} / \mathrm{hPa}$, which is established between the earthtide corrected gravity field and simultaneously recorded atmospheric pressure variations based on the method of Crossley et al. (1995).

Gaps due to power failure and offsets or spikes due to external mechanical noise are required to be filled with theoretical values using 'tsoft' toolkit30 based on long-term observation at the recording station and calculated by the interpolation method described in tsoft (Van Camp et al. 2005). The data correction methods using 'tsoft' have also been adopted in most of the processing of SG gravity data (Casula et al., 2007; Hongjuan et al., 2015). Finally, the residuals obtained after removing the tidal and atmospheric pressure effects define the temporal gravity variation.

The gravity residual contains high frequency oscillations caused by local, regional and teleseismic earthquake events. The station is situated in the high Himalayan seismic belt (Figure 2) therefore these

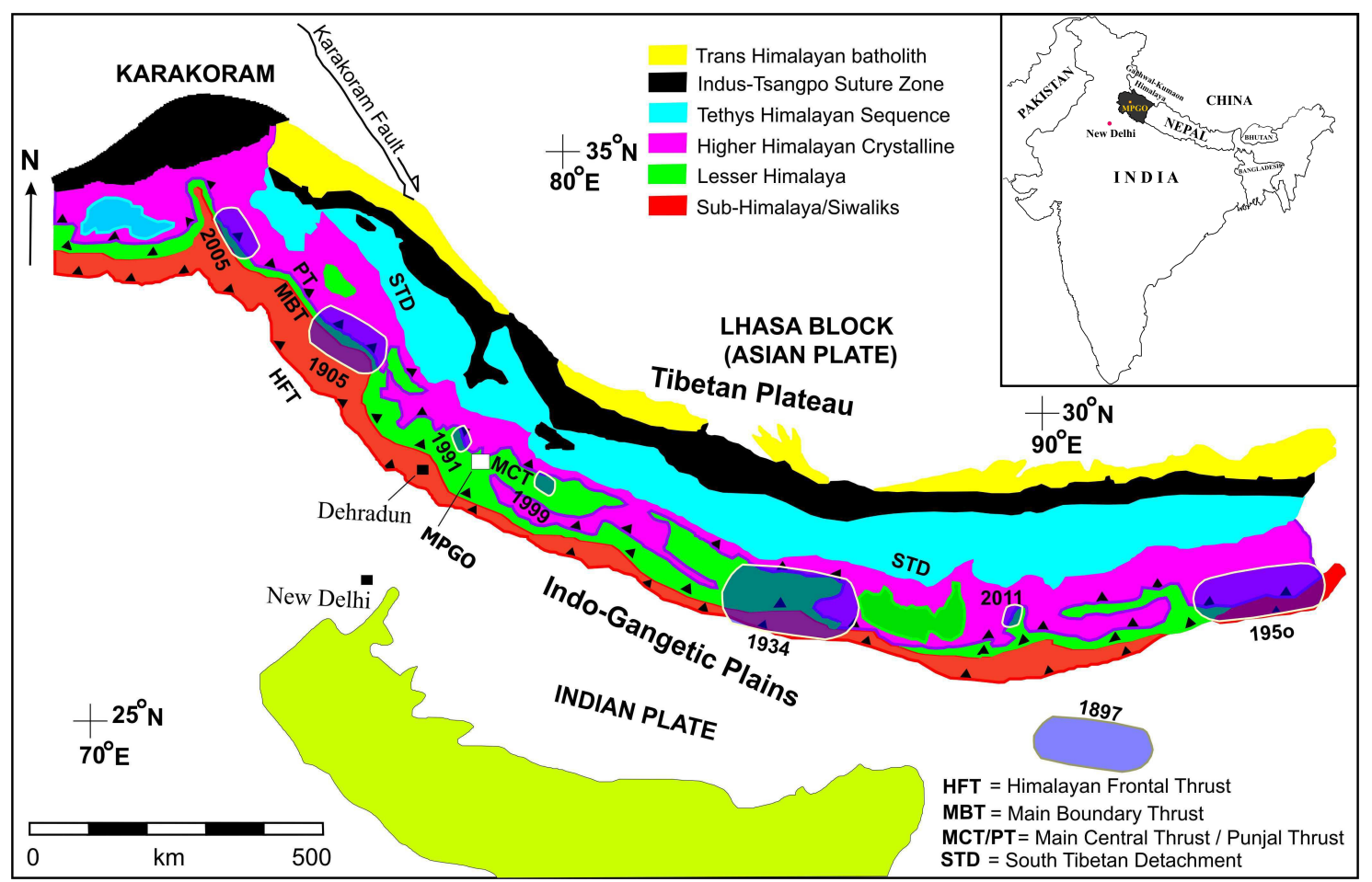

Figure 1: Location of the MPGO and geo-tectonic setting of the Himalayan region (modified after Corfield et al., 2001) and rupture zones of big earthquakes. (Inset: The study region is highlighted in black). 


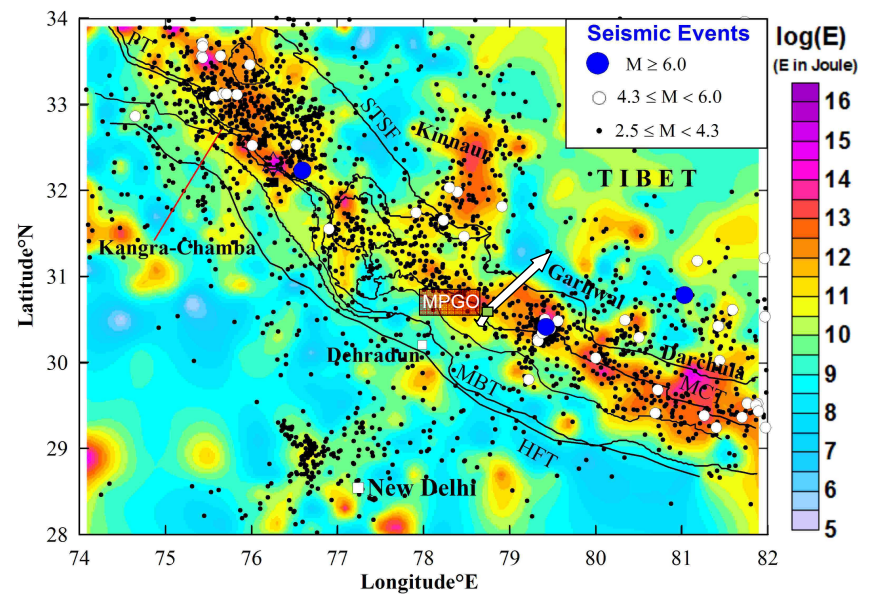

Figure 2. Present and past seismicity of NW Himalayan region for the period 1551 to 2010 based on Lyubshin et al. (2010) and Kumar et al. (2012). The observation site MPGO is shown by a small rectangle. The velocity estimates (after Khandelwal et al., 2014) for MPGO are shown by arrows. The larger arrow shows the moving rate of site in northeast direction $\left(N 47^{\circ}\right)$ in global reference frame which is about $43.3 \pm 1 \mathrm{~mm} / y e a r$. The smaller arrow shows the rate in southwest direction i.e. $6.1 \pm 1 \mathrm{~mm} / y e a r$ in Indian reference frame.

high frequency oscillations are noticed many times in daily records. The gravity time series is decimated to 1-min samples to reduce the effect of high frequency noise associated with earthquake activity. Daily mean values are computed using a moving average method to make SG data comparable with GPS values in the time domain.

The GPS data of MPGO, Ghuttu, have been analyzed together with other permanent IGS stations surrounding the Indian tectonic plate. For this purpose, we used the GAMIT/GLOBK version 10.35 (King and Bock, 2005; Herring et al., 2010a and 2010b) to evaluate the time series of site coordinates. The daily site position estimates and their rates are referenced to ITRF2008 (Altamimi et al., 2011). To compare GPS data with the gravity time series, we used the vertical component. We also computed the errors in the time series of the vertical displacement. These errors are found to vary between $5 \mathrm{~mm}$ and $14 \mathrm{~mm}$ with average value of $8.28 \mathrm{~mm}$. Khandelwal et al. (2014) estimated the site motion of MPGO, Ghuttu using GPS measurements based on five years' (2007 to 2011) data and found that the global reference frame in this site moves in northeast direction $\left(\mathrm{N} 47^{\circ}\right)$ at the rate of about $43.3 \pm 1 \mathrm{~mm} /$ year. In the Indian reference frame it moves in a southwest direction at the rate of $6.1 \pm 1 \mathrm{~mm} /$ year (Figure 2).

\section{Results and discussion}

The variations of calculated gravity residual data are displayed in Figure 3a. They clearly exhibit annual changes as high as 300-350 $\mathrm{nms}^{-2}$ with stronger variations mainly during rainy seasons. The daily vertical GPS displacement is presented in the same panel. A running average over seven days is also plotted for both time series to identify the similar patterns on longer periods. The GPS time series also shows significant annual changes but these variations are in opposite phase with respect to the SG data. Also, these variations are without artifacts of the GPS data processing related to troposphere modeling and reference frame which is defined by considering the fiducial sites in the processing (Flouzat et al, 2009; Khandelwal et al., 2014).

In Figure $3 b$, we plotted the variations in water table and rainfall recorded at the same site. Rainfall in the Himalayan region occurs mainly in the monsoon season (July to September) and therefore causes seasonal hydrological variations/cycles. Water level is correlated with rainfall because it increases with rainfall and decreases due to discharge processes. In this Figure 3 the hydrological changes are clearly visible with strong influence on both time series. During ground water level increase in the rainy season, an increase is noticed in gravity while a significant downward crustal motion is noticed in the vertical displacement. On the other hand, as the water level starts decreasing in winter a decreasing trend is observed in gravity and upward vertical motion in the GPS time series. This relation clearly indicates the loading effect due to the hydrological cycle. We quantified the correlation between gravity and vertical displacement for different time periods. The maximum negative correlation coefficient of -0.5 and -0.6 is observed in the rainy seasons of 2007 and 2008 respectively. The maximum water table change occured in the rainy seasons which is $1112.05 \mathrm{~cm}, 1589.6 \mathrm{~cm}$, and $971.05 \mathrm{~cm}$ in 2007, 2008 and 2009 respectively.

Along with these longer period trends observed in gravity and GPS data, we also studied the short-term variations in both data sets. The main sources of short-term changes are the high frequency vibrations due to earthquakes and hydrological effects during heavy and persistent rainfall. Small-scale variations due to rainfall cannot be seen in the daily GPS time series while persistent long-period rainfall causes sufficient amount of water in the underground and may affect this time series due to the loading effect. In the case of gravity, small-scale variations are noticed during heavy rainfall events as well as continuous rainfall affecting the long-term trend. As aforesaid, there is a directed correlation of rainfall and water level which leads to the changes in gravity values.

The Newtonian attraction due to accumulation of underground water as the resultant of rainfall or soil moisture below the sensor and vertical displacement are main factors for significant changes in gravity data (Amalvict et al., 2004; Imanishi et al., 2006). To separate both these effects we attempted to model the incremental water storage effects on gravity using the data of rainfall precipitation. We applied the tank model of Imanishi et al. (2006) which has successfully removed the hydrological changes from gravity data. In this connection, first we calculated the ratio of gravity residual and the
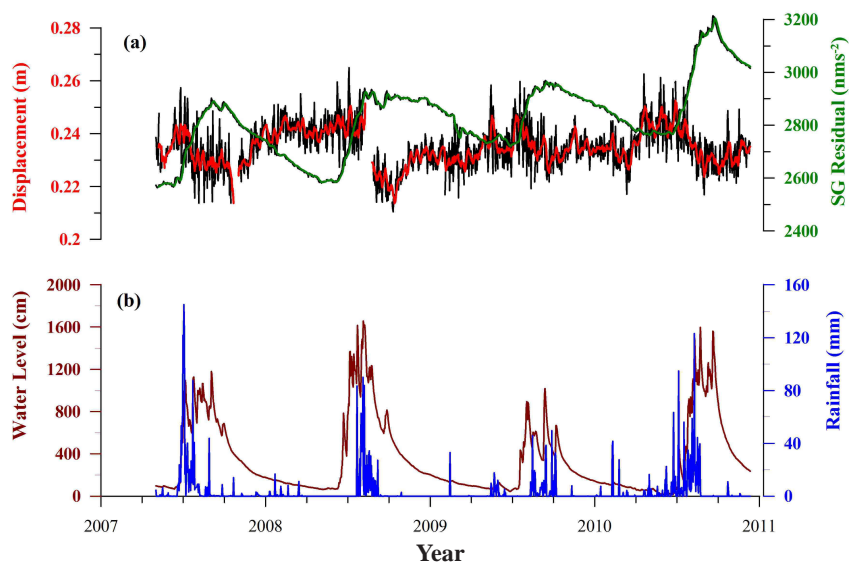

Figure 3: (a) Variation of daily GPS vertical displacement (left axis) and variation of daily mean of residual gravity data (right axis) at MPGO, Ghuttu. Running mean over seven days is also plotted (green line for gravity and red line for GPS). (b) Water level variations (left axis) and daily rainfall (right axis). 

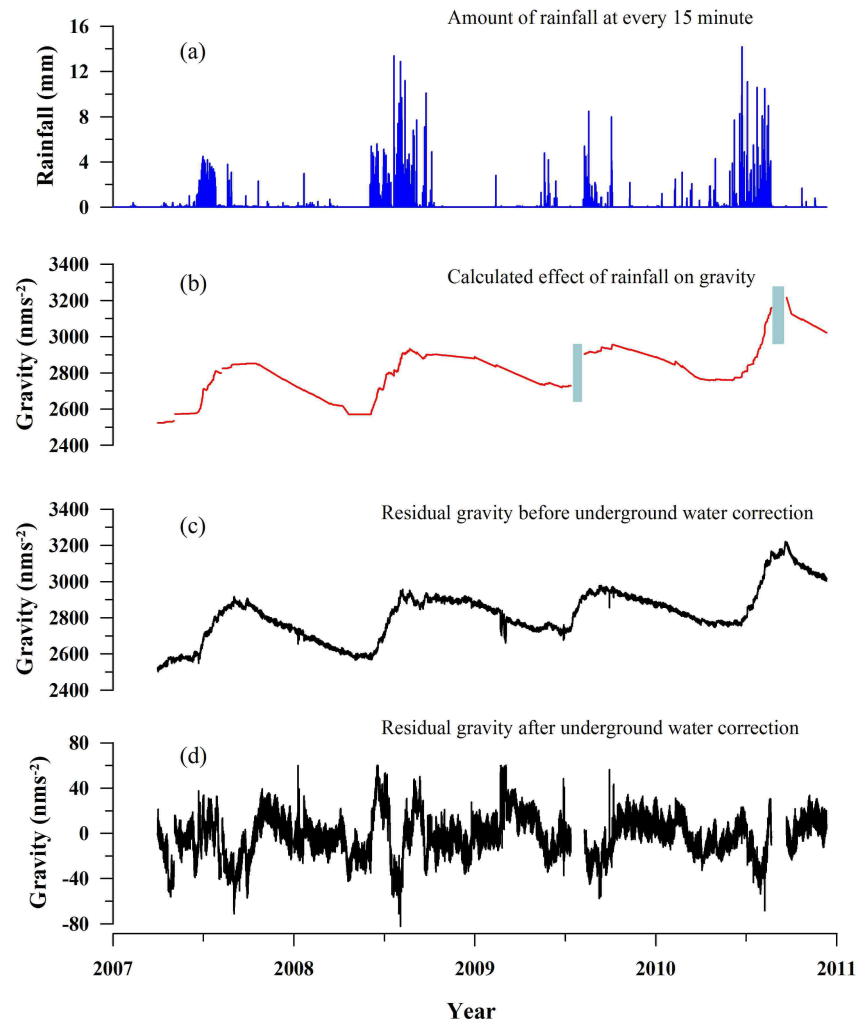

Figure 4. (a) Amounts of rainfall at every 15 minute. (b) Calculated effect of rainfall on gravity. (c) Residual gravity before underground water correction. (d) Residual gravity after underground water correction.

rainfall amount which resulted in the average admittance of rainfall $\sim 0.2 \mathrm{nms}^{-2} \mathrm{~mm}^{-1}$ on gravity. Further, theoretical values of gravity were calculated using a differential equation and utilizing Heaviside step function as per the procedure adopted by them. The $\alpha$ and $\gamma$ constants of the differential equation (equation 1 of Imanishi et al., 2006) are positive with values $0.2 \mathrm{nms}^{-2} \mathrm{~mm}^{-1}$ and $3.5 \times 10^{-19} \mathrm{~ms}^{-3}$ respectively. The results are plotted in Figure 4 where we calculated the residual after removing the effect of modeled gravity variation giving the results shown in Figure 4d. Sometimes there is break in the rainfall data for which period it is not possible to calculate the theoretical values and there are small breaks on two occasions in the corrected residual gravity. The residual gravity is found to vary within $\pm 40 \mathrm{nms}^{-2}$ by applying the underground water correction. After removing the underground water effect or the Newtonian effect, it can be concluded that the variation in the remaining residual gravity may be the cause of vertical displacement.

The correlation between temporal variations in SG and in vertical crustal deformation data has also been performed in other parts of the globe (Zerbini et al., 2001; Amalvict et al., 2004; Francis et al., 2004; Rosat et al., 2009). Amalvict et al. (2004) studied gravity data using SG and AG at Strasbourg station, France for two continuous durations of 9 years and 6 years respectively. They found a long-term trend of $15.7 \mathrm{nms}^{-2} /$ year in gravity data with quasi-annual variations, which were interpreted in terms of the annual cycle of the regional Alsace Plain water table with maximum changes as $0.4 \mathrm{~m}$ for a data of $\sim 4$ years period. However, by comparing GPS and gravity data they also observed small annual variations in vertical displacements. Their observations reported the rate of vertical displacement at this station as $-0.9 \mathrm{~mm} /$ year. Within the observation period of four years at MPGO,
Ghuttu, we observed the annual variations in gravity data at the rate of $112 \mathrm{nms}^{-2} /$ years while the maximum change in water table was 16 $\mathrm{m}$. The observed rate of vertical displacement for the same period of 4 years was $2.2 \mathrm{~mm} /$ year.

Zerbini et al. (2010) studied the relationship of gravity variation and fluctuations in the GPS vertical component along with the hydrological time series collected by the stations in northeastern Italy. They observed a clear seasonal signal in both of the time series of GPS and SG. They also found a negative correlation between the two data sets. Jin et al. (2012) also found a negative correlation between the gravity data of SG and vertical deformation of the GPS station.

\section{Conclusion}

Simultaneous data of gravity and vertical crustal displacements monitored by a superconducting gravimeter and GPS respectively show clear annual or seasonal variations. These seasonal variations are due to hydrological load changes. High precipitation during monsoon (July - September) influences the level of water table. The annual cycle of the gravity variation is in phase with the water level while the vertical crustal motion has an opposite phase. Therefore, gravity and vertical displacement show negative correlation with extremes during the rainy seasons. The loading effect due to increased level of underground water exerts a force on the earth surface pushing it downwards, which is visible in low vertical displacement values during the rainy season. Therefore, gravity increases in the rainy season, which is interpreted in terms of Newtonian attraction and vertical displacement. In summer, reverse behavior is noticed in both time series due to less water loading.

\section{Acknowledgements}

The authors thank the Director, Wadia Institute of Himalayan Geology (WIHG), Dehra Dun, India for permission to publish this work. The Ministry of Earth Science, Government of India is acknowledged for providing funds through a project (MoES/P.O. (Seismo)/NPEP(15)/2009). Continued support and encouragement by the Chairman and other members of Project Management Board are acknowledged. The Head, Geo-sciences and Coordinator at the MoES provided support and guidance. Two anonymous reviewers are thanked for their valuable comments that helped to improve the manuscript.

\section{References}

Aktuðg, B., Meherremovb, E., Kurtc, M., Ozdemirc, S., Esedovb, N., Lenkc, O., 2013, GPS constraints on the deformation of Azerbaijan and surrounding regions: Journal of Geodynamics, v. 67, pp. 40-45.

Altamimi, Z., Collilieux, X., Métivier, L., 2011, ITRF2008: an improved solution of the international terrestrial reference frame: Journal of Geodesy, doi:10.1007/s00190-011-0444-4.

Amalvict, M., Hinderer, J., M“akinen, J., Rosat, S., Rogister, Y., 2004, Longterm and seasonal gravity changes at the Strasbourg station: Journal of Geodynamics, v. 38, pp. 343-353.

Arora, B.R., Kamal, Kumar, A., Rawat, G., Kumar, N., Choubey, V.M., 2008, First observations of free oscillations of the earth from Indian superconducting gravimeter in Himalaya: Current Science, v. 95, no. 11, pp. 1611-1617.

Arora, B.R., Rawat, G., Kumar, N., Choubey, V.M., 2012, Multi-Parameter Geophysical Observatory: gateway to integrated earthquake precursory research: Current Science, v. 103, no. 11, pp. 1286-1299.

Banerjee, P., Burgmann, R., 2002, Convergence across the northwest Himalaya 
from GPS measurements: Geophysical Research Letter, v. 29, no. 13, pp. 1652 (1-4).

Bettinelli, P., Avouac, J.P., Flouzat, M., Bollinger, L., Ramillien, G., Rajaure, S., Sapkota, S, 2008, Seasonal variations of seismicity and geodetic strain in the Himalaya induced by surface hydrology: Earth and Planetary Science Letter, v. 266, pp. 332-344.

Burgmann, R., Larson, K., Bilham, R., 1999, Model inversion of GPS and leveling measurements across the Himalaya: implications for earthquake hazards and future geodetic networks: Himalayan Geology, v. 20, pp. 59-72.

Casula G., Danesi, S., Dubbini, M., Vittuari, L., 2007, Tidal forcing on David Glacier and Drygalski Ice Tongue in the 10th ISAES X Online Proceedings, in Antarctica: A Keystone in a Changing World - Online Proceedings of the 10th ISAES X, edited by A. K. Cooper and C. R. Raymond et al., USGS Open-File Report 2007-1047, Extended Abstract 009 , pp.4.

Corfield, R.I., Searle, M.P., Pedersen, R.B., 2001, Tectonic setting and obduction history of the Spontang Ophiolite, Ladakh Himalaya, NW India: Journal of Geology, v. 109, pp. 715-736.

Crossley, D.J., Jensen, O.G., Hinderer, J., 1995, Effective barometric admittance and gravity residuals: Physics of the Earth Planetary Interiors, v. 90, pp. 221-241.

Crossley, D., Hinderer, J., Boy, J.P., 2004, Regional gravity variations in Europe from superconducting gravimeters: Journal of Geodynamics, v. 38, pp. 325-342.

Flouzat, M., Bettinelli, P., Willis, P., Avouac, J.P., He'ritier, T., Gautam, U., 2009, Investigating tropospheric effects and seasonal position variations in GPS and DORIS time-series from the Nepal Himalaya: Geophysical Journal International, v. 178, pp. 1246-1259.

Francis, O., Camp, M.V., Dam, T.V., Warnant, R., Hendrickx, M., 2004, Indication of the uplift of the Ardenne in long-term gravity variations in Membach (Belgium): Geophysical Journal International, v. 158, pp. 346-352.

Fu, Y. and Freymueller, J.T., 2012, Seasonal and long-term vertical deformation in the Nepal Himalaya constrained by GPS and GRACE measurements: Journal of Geophysical Research, v. 117 no. (B03407), pp. 1-14.

Gahalaut, V.K., Chander, R., 1997, On interseismic changes and strain accumulation for great thrust earthquakes in the Nepal Himalaya: Geophysical Research Letter, v. 24, pp. 1011-1014.

Gahalaut, V.K., Chander, R., 1999, Geodetic evidence for accumulation of earthquake generating strains in the NW Himalaya near $75.5^{\circ} \mathrm{E}$ longitude: Bulletin of Seismological Socitey of America, v. 89, pp. 837-843.

Gahalaut, V.K., Kundu, B., 2012, Possible influence of subducting ridges on the Himalayan arc and on the ruptures of great and major Himalayan earthquakes: Gondwana Research, v. 21, pp. 1080-1088.

Herring, T.A., King, R.W., McClusky, S.C., 2010a, Documentation of the GAMIT GPS Analysis Software release 10.4, Department of Earth and Planetary Sciences, Massachusetts Institute of Technology, Cambridge, Massachusetts.

Herring, T.A., King, R.W., McClusky, S.C., 2010b, GLOBK, Global Kalman ûlter VLBI and GPS analysis program, version 10.4, Department of Earth and Planetary Sciences, Massachusetts Institute of Technology, Cambridge, Massachusetts.

Hongjuan, Y., Jinyun, G., Jiulong, L., Dapeng, M., Qiaoli, K., 2015, Zero drift and solid Earth tide extracted from relative gravimetric data with principal component analysis: Geodesy and Geodynamics, http:// dx.doi.org/10.1016/j.geog.2015.01.006.

Imanishi, Y., Kokubo, K., Tatehata, H., 2006, Effect of underground water on gravity observation at Matsushiro, Japan: Journal of Geodynamics, v. 41, pp. 221-226.

Jackson, M.E., Bilham, R., 1994, 1991-1992 GPS measurements across the
Nepal Himalaya: Geophysical Research Letter, v. 21, no. 12, pp. 11691172 .

Jin, W., Hui, L., Wen-Bin, S., Kai-Xuan, K., Hong-Tao, H., 2012, An analysis to observations of the superconducting gravimeter at the Jiufeng seismic station, Wuhan: Chinese Journal of Geophysics, v. 55, no. 4, pp. 409417.

Khandelwal, D.D., Gahalaut, V., Kumar, N., Kundu, B., Yadav, R.K., 2014, Seasonal variation in the deformation rate in NW Himalayan region: Natural Hazards, v. 74, pp. 1853-1861.

Khandelwal, D.D., Gupta, A.K., Chauhan, V., 2015, Observation of rainfall in Garhwal Himalaya, India during 2008-2013 and its correlation with TRMM data: Current Science, v. 108, no. 6, pp. 1146-1151.

King, R.W., Bock, Y., 2005, Documentation of the GAMIT GPS analysis software release 10.2, report. Mass. Inst. of Technology, Cambridge.

Kumar, N., Paul, A., Mahajan, A.K., Yadav, D.K., Bora, C., 2012, The $M w$ 5.0 Kharsali, Garhwal Himalayan earthquake of 23 July 2007: source characterization and tectonic implications: Current Science, v. 102, no. 12, pp. 1674-1682.

Kumar, N., Rawat, G., Choubey, V.M., Hazarika, D., 2013, Earthquake precursory research in western Himalaya based on the Multi-Geophysical Observatory data: Acta Geophysica, v. 61, no. 4, pp. 977-999.

Lyubushin, A. A., Arora, B. R., Kumar, N., 2010, Investigation of seismicity in western Himalaya: Russion Journal of Geophysical Research, v. 11, pp. $27-34$

Pandey, M. R., Tandulkar, R.P., Avouac, J.P., Lave, J., Massot, J.P., 1995, Interseismic strain accumulation in the Himalayan crustal ramp in Nepal: Geophysical Research Letter, v. 22, pp. 741-754.

Ponraj, M., Miura, S., Reddy, C.D., Prajapati, S.K., Amirtharaj, S., Mahajan, S.H., 2010, Estimation of strain distribution using GPS measurements in the Kumaun region of Lesser Himalaya: Journal of Asian Earth Sciences, v. 39, pp. 658-667.

Rosat, S., Boya, J.P., Ferhata, G., Hinderera, J., Amalvicta, M., Gegouta, P., Lucka, B., 2009, Analysis of a 10-year (1997-2007) record of timevarying gravity in Strasbourg using absolute and superconducting gravimeters: New results on the calibration and comparison with GPS height changes and hydrology: Journal of Geodynamics, v. 48, pp. 360365.

Van Camp, M., Vauterin, P., 2005, Tsoft: graphical and interactive software for the analysis of time series and Earth tides: Computers \& Geosciences, v. 31, no. 5, pp. 631-640.

Van Camp, M., Métivier, L., de Viron, O., Meurers, B., Williams, S. D. P., 2010, Characterizing long time scale hydrological effects on gravity for improved distinction of tectonic signals: Journal of Geophysical Research, v. 115, B07407,doi:10.1029/2009JB006615.

Wenzel, H.G., 1996, The nanogal software: earthtide data processing package ETERNA 3.3.: Bulletin d' Informations Maree's Terrestres, Bruxelles, v. 124, pp. 9425-9439.

Wilmes, H., Boer, A., Richter, B., Harnisch, M., Harnisch, G., Hase, H., Engelhard, G., 2006, A new data series observed with the remote superconducting gravimeter GWR R038 at the geodetic fundamental station TIGO in Concepción (Chile): Journal Of Geodynamics, v. 41, pp. 5-13.

Zerbini, S., Richter, B., Negusini, M., Romagnoli, C., Simon, D., Domenichini, F., Schwahn, W., 2001, Height and gravity variations by continuous GPS, gravity and environmental parameter observations in the southern Po Plain, near Bologna, Italy: Earth and Planetary Science Letter, v. 192, pp. 267-279.

Zerbini, S., Raicich, F., Richter, B., Gorini, V., Errico, M., 2010, Hydrological signals in height and gravity in northeastern Italy inferred from principal components analysis: Journal of Geodynamics, v. 49, pp. 190-204. 